\title{
Grandparental Childcare and Second Birth in China: Evidence from a Dynamic Model and Empirical Study
}

\author{
Ye Wang ${ }^{1}$ and Xindong Zhao iD $^{2}$ \\ ${ }^{1}$ School of Economics and Finance, Huaqiao University, Xiamen 361021, China \\ ${ }^{2}$ School of Statistics, Huaqiao University, Xiamen 361021, China \\ Correspondence should be addressed to Xindong Zhao; xzhao@hqu.edu.cn
}

Received 7 October 2020; Revised 17 April 2021; Accepted 24 May 2021; Published 2 June 2021

Academic Editor: Yu-Wang Chen

Copyright $\odot 2021$ Ye Wang and Xindong Zhao. This is an open access article distributed under the Creative Commons Attribution License, which permits unrestricted use, distribution, and reproduction in any medium, provided the original work is properly cited.

\begin{abstract}
The availability of nonparental childcare may be an important factor that influences reproductive decisions. While there is still a shortage of formal childcare service in China, grandparents are one primary source of childcare for their grandchildren. However, impact evaluations regarding the contribution of grandparenting on fertility level in China are still limited; the established evaluation results are not conclusive, especially for the birth of the second child. In this paper, we provide a theoretical justification and an empirical study of the influence of grandparental childcare on the second birth. By introducing a dynamic general equilibrium (DGE) model, this study proves that intergenerational childcare plays a critical role in both boosting the fertility level and maintaining its positive tendency. Drawing on the nationally representative data from the China Migrants Dynamic Survey in 2016, we estimate the treatment effects of grandparental childcare for the first child on the second birth with the Propensity Score Matching method. After controlling the self-selection bias, the results show that intergenerational childcare can positively affect the second birth. Sensitivity analysis results show the relative robustness of our empirical estimates to potential hidden bias attributed to unobserved variables. We also draw policy implications from the analysis, calling for government policies not only to promote sustainable and healthy development of the childcare industry but also to support family life, especially grandparental childcare.
\end{abstract}

\section{Introduction}

Due to decades of falling birth rates and increase in life expectancy in China, population aging, a significant obstacle to social and economic development, is becoming a pressing issue that needs to be resolved. According to the China Statistical Yearbook in 2020 [1], the number of elderly people aged 65 and over was 138 million in 2014. However, this number has risen to 176 million in 2019 [1]. While the elderly population increases rapidly, the birth rate continues to decline, which is widely perceived as a significant obstacle for the development of the labor force in China in the decades to come. In 2014, the birth rate in China was only $12.37 \%$. To reverse the sinking birth rate and ease the pressure from population aging, the Chinese government has replaced the one-child policy with the universal two-child policy in Jan. 2016 and allows all couples to have two children. However, despite a two-year increase immediately afterwards due to an accumulative effect, the birth rate fell to $10.48 \%$ in 2019 [1], the lowest in seven decades. According to the National Fertility Survey conducted in 2017, although the proportion of couples with the ideal number of two children has increased significantly, the proportion of couples actually planning to have a second child has obviously declined [2]. Giving birth to a second child is a multifaceted issue and strongly related to a longterm plan.

Besides the high cost of raising a child, another critical reason that holds back the willingness of young couples to have a second child is the lack of childcare, especially for working mothers $[3,4]$. Currently, there is significantly increased workforce participation for women in China, and 
two-career families are prevalent and popular, especially in urban households. Childcare, especially under the norm of intensive parenting, takes a nonnegligible fraction of the time of the working parents. Challenged by both working pressure and parenting burden, dual-earner couples are usually forced to seek additional support for childcare, which is a factor that may influence reproductive decisions $[5,6]$. While the demands for childcare services keep increasing, there is still an insufficient supply of childcare agencies and affordable and quality childcare services in China. Thus, many families still rely on their family members, especially grandmothers, for childcare. Indeed, grandparents have been one of the primary providers of childcare for grandchildren in China [7], which entails a more comprehensive understanding of the impact of intergenerational childcare on the fertility rate, especially the birth of the second child, in China.

Different from the relatively independent family culture in Europe and America, Chinese families, which are influenced by Confucian culture, are arguably more closely knitted, which results in a closer bond between the grandparents and their offsprings. Downward intergenerational time transfers in the form of grandchild care are common in China. About $40 \%$ of elderly people in China involve in intergenerational childcare in China [8], and intergenerational childcare in rural areas is more common [9] than in urban areas. Thus, the availability of intergenerational child care has a significant impact on the fertility, work, and life of reproductive age couples $[6,10]$, especially for two-career households.

In this study, we use the nationally representative household data drawn from the China Migrants Dynamic Survey in 2016 (CMDS 2016), a large-scale survey of domestic migrant population in China, to investigate the influence of intergenerational childcare. The migrants in the CMDS refer to the population living away from their registered household residence for over one month. The domestic migrant population in 2017 was 244 million in China, according to the Report on China's Migrant Population Development in 2018, and the fertility rate of the second child in the migrant population has a significant impact on the fertility rate in China.

Grandparenting is common in the migrant population due to the distinctive demand for nonmaternal childcare. The particularity of migrant households has a significant influence on their child-rearing modes and fertility desire. According to the different family arrangements for childcare, there are usually three ways to rear their children when both the parents work away from home. (1) When the grandparents also move with their offspring, the children are jointly raised by their parents and grandparents. (2) When only the children move with their parents, they are taken care of by their parents. (3) When the children are left behind in the hometown, they are mainly taken care of by their grandparents and are usually called left-behind children. According to the 1\% National Population Sample Survey (NPSS) of China conducted in 2015, over 68 million children are left behind nationwide in 2015, and over 40 million live in rural areas. Half of the left-behind children in rural areas could only live with their grandparents or other caretakers.

1.1. Previous Literature. A growing recent literature investigates the varied roles [11-14] of intergenerational childcare (or time transfer) provided by grandparents, which is usually driven by altruistic motives, exchange motives, and emotional motives $[11,15,16]$. While there has been a general consensus that grandparental childcare increases the labor force participation of young mothers $[12,13,17]$, studies on the impact of intergenerational childcare on fertility, especially on the birth of the second child, are still limited. The existing research about the effects of the intergenerational childcare on fertility can basically be grouped into two categories, i.e., theoretical analysis and empirical study. As a theoretical study, Fanti and Gori [17] utilized the overlapping generation (OLG) model to study the effect of longevity on fertility in the context of intergenerational childcare. They found that the increasing longevity causes fertility to increase or decrease depending on the length of intergenerational childcare time. However, they simply regarded the fraction of time allocated for intergenerational childcare as an exogenous constant that does not change over different generations and, thus, lacked a detailed discussion of the intergenerational childcare mechanism. Wang [18] improved the model of Fanti and Gori [17] by taking intergenerational childcare time as an endogenous variable that varies over generations. They showed that the increase of grandparental childcare time would decrease the parental childcare time and, thus, promote fertility. However, their model assumed that alimony is the reward of the time spent on the care of their grandchildren. Without taking care of grandchildren, the grandparents will receive no alimony from their offsprings, which is not in accordance with the actual situation in China. In fact, most of the grandparents who choose to take care of grandchildren are not entirely driven by financial rewards but more driven by emotional motives and altruistic motives: the well-being of their children and grandchildren and the development of the whole family. Moreover, the model in [18] only considered the time cost of raising a child but ignored the finical cost. Zhou [19] also used the OLG model and suggested that postponing the retirement policy would reduce intergenerational childcare time and lower fertility. While previous theoretical studies have laid a sound research foundation for this topic, we will further address the issues mentioned above with an econometric model that is calibrated to be more in line with the tradition and reality in China.

Given the existing empirical research, whether grandparental childcare is associated with higher fertility levels is still harder to answer, as the existing empirical evidence has been mixed and varies by country. For example, Tanskanen and Rotkirch [20] investigated the impact of grandparental investment on mothers' fertility intentions in four European countries. They found that, while grandparental childcare help was associated with increased fertility intentions in France and Norway, childcare help from grandparents was associated with decreased intentions in Lithuania. Using the 
panel data of several European countries, Aassve et al. [21] showed the critical role of grandparenting in individuals' decision making for having more children, especially in the South of Europe, where formal childcare services were limited. Based on the longitudinal data of the Netherlands in 1992, Kaptijn et al. [22] showed that grandparental childcare support would increase the probability that parents have more children. In contrast, using longitudinal data in the UK, Waynforth [23] showed that grandparenting is not significantly positively associated with births, although the closeness of the bond between young couples and their parents were shown to be associated with an increased likelihood of having another child. Using the data in South Korea, Yoon [24] found that supportive environments, including grandparental childcare assistance for the family, have a more substantial effect on fertility behavior than fertility intentions. Based on a survey data from Tianjin, a typical city in the north of China, Zhang [4] explored the factors that may influence the second-birth plan of young couples and found that the availability of grandparental childcare for a second child is an essential factor. Utilizing an earlier survey data of 12 Chinese cities in 2016 when the universal two-child policy has just released, Jin et al. [25] investigated the impact of grandparents' supports and fertility preference on the second-birth plan of young women with a logistic model and showed that the availability of grandparental childcare for a second child would increase the probability of planning to have a second child. Using data from CMDS 2016, Yang [3] investigated the secondbirth intention of internal migrants who already have the first child with a logistic model. Note that there is usually a gap between intending to give the second birth and actually giving birth to the second child [26]. In this study, we further investigate the treatment effect of grandparental childcare for the first child on giving birth to a second child with the data from CMDS 2106 while controlling overt and hidden selection biases.

Although many studies $[3,4,21,24]$ have suggested that intergenerational childcare had an impact on the birth of children, the impact evaluations are usually limited to birth plan or fertility intension, and evaluation results are also not conclusive, especially for the birth of the second child. For example, using the survey data of Beijing, Wang and Yang [26] have shown the possible reverse effect of leaving the child behind with the grandparents on the willingness to have a second child. Moreover, while most studies rely on logistic regression and its improved models to explore the association between of intergenerational childcare and the birth of children, there may be overt and hidden biases in estimating causality between intergenerational childcare and birth of children. Therefore, the treatment effect of intergenerational childcare needs further investigation. Furthermore, the research on "leftbehind" and "migratory-bird" intergenerational childcare in [26] relied only on the data of city-wide questionnaire survey with a small sample size and limited survey scope. Whether intergenerational childcare significantly impacts the birth of the second child requires further study and discussion.
1.2. Research Framework. This paper conducts both theoretical analysis and empirical study to explore the impact of intergenerational childcare on the birth of the second child. To this end, we first introduce a dynamic general equilibrium (DGE) model calibrated to be more in line with the national conditions of China. The numerical simulation results show that, with the increase of life expectancy, the hours that can be invested in grandparenting and the number of births will also increase; grandparenting is an important factor that not only can boost the fertility level but also can help maintain its positive trend. Then, we conduct empirical analysis using the nationally representative data of CMDS2016, with which we mainly explore the impact of having grandparental childcare for the first child on the birth of the second child. To deal with self-selection bias in this observational study, we estimate the treatment effects by using propensity score matching (PSM) [27, 28], which shows the positive treatment effect of grandparenting on the birth of the second child. We also complement the PSM estimation with sensitivity analysis, which is conducted to evaluate the robustness of the treatment estimates to potential hidden bias, and subgroup analysis, which evaluates the potential group heterogeneity. We believe that our findings will contribute to efforts in designing effective policies to boost fertility. We also draw policy implications from the analysis, calling for family-friendly policies to support intergenerational childcare.

The remainder of this paper is organized as follows. Section 2 introduces the theoretical model and the simulation results. Section 3 describes the empirical study. Section 4 concludes the study.

\section{Theoretical Analysis}

2.1. The Proposed Econometric Model. In this study, we consider the closed economy populated by perfectly rational and identical individuals and develop a DGE model consisting of individuals and firms under the market clearing assumption. Our objective is to devise a model that is not only consistent with the "trend" facts but can also replicate the cyclical properties of a household.

2.1.1. Typical Individuals. Based on the life-cycle theory for individuals, each individual's life within each generation consists of three periods, i.e., childhood, young age, and old age. Individuals exclusively make economic decisions in the working and retirement periods, i.e., the young age and old age. Thus, we choose to omit childhood in the introduced econometric model. We also assume that the length of young age is one unit of time and the length of old age is $\rho$. Therefore, the value of $\rho$ indicates the lifespan of individuals. Typical individuals have preferences towards consumption, leisure, and the number of children and make a series of choices and decisions during their lifetime to maximize the expected lifetime utility. Accordingly, we construct an OLG model with the inheritance as an additional factor to match the stylized facts in China. Figure 1 presents an overview of the structure of the developed OLG model for typical 
individuals. Intergenerational transfer of time and capital, in the form of grandparenting, alimony, and inheritance, and intertemporal transfer of capital are considered. Individuals receive inheritances from their parents (previous generation) at the young age (working period) and give inheritance to their children (next generation) at the old age (retirement period). Besides, considering the law and situation in China, individuals give a fixed percentage of income as alimony to their parents and upbringing payment to their children at their young age.

At the $t$ period, the decision variables for each young individual include the working time $l_{t}$, the savings $s_{t}$, and the number of children $2 n_{t}$ with her/his spouse (each fosters $n_{t}$ children on average). At the $t+1$ period, these individuals come to their old age and the variables they could decide are intergenerational childcare time $z_{t+1}$ for each grandchild and the inheritance $O_{2, t+1}$ giving to their children. For each individual, these five variables decide the consumption $c_{1, t}$ at the young age, the consumption $c_{2, t+1}$ at the old age, the leisure time $h_{1, t}$ at the young age, and the leisure time $h_{2, t+1}$ at the old age. Accordingly, the total utility of each individual is

$$
\begin{aligned}
U_{t}= & \log c_{1, t}+\gamma \log h_{1, t}+\beta \rho \log c_{2, t+1}+\beta \gamma \log h_{2, t+1} \\
& +\theta \log n_{t}+\tau \log O_{2, t+1},
\end{aligned}
$$

where $U_{t}$ is the utility of the individual who is at young age at the $t$ period, $\beta$ is the discount factor, $\gamma$ is the extent of the preference to leisure, $\theta$ is the utility coefficient obtained from the company of children, and the coefficient $\tau$ is the extent of the preference of granting inheritance to their offsprings.

We further assume that each individual gives a fixed percentage $\eta$ of the income at young age as alimony to their parents, since grown-up children in China have the duty to support and assist their parents. In this way, the increase of children's income will increase the elderly parents' alimony from their children, which further motivates the behavior of intergenerational childcare indirectly. Let the cost of raising each child be a fixed percentage $\mu$ of the income, and the number of children raised by each individual is $n_{t}$; then, the actual income available at the young age for consumption and saving is $w_{t} l_{t}\left(1-\eta-\mu n_{t}\right)$. Assuming that the inheritance $O_{2, t}$ is divided equally among the $n_{t-1}$ children, each individual would get $O_{2, t} / n_{t-1}$ inheritance from their parents. The consumption and saving of each individual at the young age is subject to the following equality constraint:

$$
c_{1, t}+s_{t}=w_{t} l_{t}\left(1-\eta-\mu n_{t}\right)+\frac{O_{2, t}}{n_{t-1}},
$$

where $w_{t}$ is the wage rate in the $t$ period.

Suppose each individual has $n_{t}$ children at her/his young age (i.e., the $t$ period), the expected salary rate of her/his child at the $t+1$ period, which is the young age of the child and old age of the individual, is $w_{t+1}^{e}$, and the expected working time of each child is $l_{t+1}^{e}$. Then, the total alimony obtained from the $n_{t}$ children is $w_{t+1}^{e} l_{t+1}^{e} \eta n_{t}$. Moreover, suppose that each old-age individual would spend the savings obtained at her/his young age and the alimony from her/his children on consumption and gift inheritance to her/ his children; then, we can obtain the following constraint:

$$
\rho c_{2, t+1}+O_{2, t+1}=R_{t+1} s_{t}+w_{t+1}^{e} l_{t+1}^{e} \eta n_{t},
$$

where $R_{t+1}$ is the interest rate at the $t+1$ period. Suppose that the time cost of raising a child at the period $t$ is $E$, which is shared by the parents (at young age) and grandparents (at old age) together. Suppose the expected number of children of each adult individual at the $t+1$ period is $n_{t+1}^{e}$; then, the total number of grandchildrens of an old-age individual at this period is $n_{t+1}^{e} n_{t}$. At the $t$ period, each individual at young age allocates the time to childcare, working, and leisure; each individual at old age allocates the time to intergenerational childcare and leisure. Thus, the time constraint functions are as follows:

$$
\begin{aligned}
h_{1, t} & =1-l_{t}-n_{t}\left(E-z_{t}\right), \\
h_{2, t+1} & =\rho-n_{t+1}^{e} n_{t} z_{t+1} .
\end{aligned}
$$

Under the constraints of equations (2)-(5), each typical individual chooses working time $l_{t}$, saving $s_{t}$, fertility $n_{t}$, grandparenting time $z_{t+1}$ at her/his old age, and inheritance $\mathrm{O}_{2, t+1}$ to maximize the expected lifetime utility function (1), which is an intertemporal dynamic process since the utility depends not only on the decision of $l_{t}, s_{t}, n_{t}, z_{t+1}$, and $O_{2, t+1}$ but also on the intergenerational childcare time and inheritance from the last generation and the alimony from the next generation.

2.1.2. Firms. Suppose that technological progress is an exogenous variable and firms have identical Cobb-Douglas production functions.

$$
Y_{t}=A K_{t}^{\alpha} L_{t}^{1-\alpha}
$$

where $K_{t}$ is the capital input, $A$ denotes the total factor productivity that affects all firms, $\alpha$ is the elasticity of the capital output, $L_{t}$ is the labor input, and $Y_{t}$ is the total production. When the profit of a firm reaches its maximum, the wage rate and interest rate satisfy the following constraints:

$$
\begin{aligned}
& w_{t}=(1-\alpha) A k_{t}^{\alpha}, \\
& R_{t}=\alpha A k_{t}^{\alpha-1},
\end{aligned}
$$

where $k_{t}=K_{t} / L_{t}$ denotes the average amount of labor capital.

2.1.3. Market Clearing Condition. Suppose that the total number of individuals at young age in the $t$ period is $N_{t}$; then, the total number of individuals at the young age at the $t+1$ period satisfies the equation

$$
N_{t+1}=N_{t} n_{t} \text {. }
$$

The labor supply equals the labor demand when the market clears at the $t$ period. 


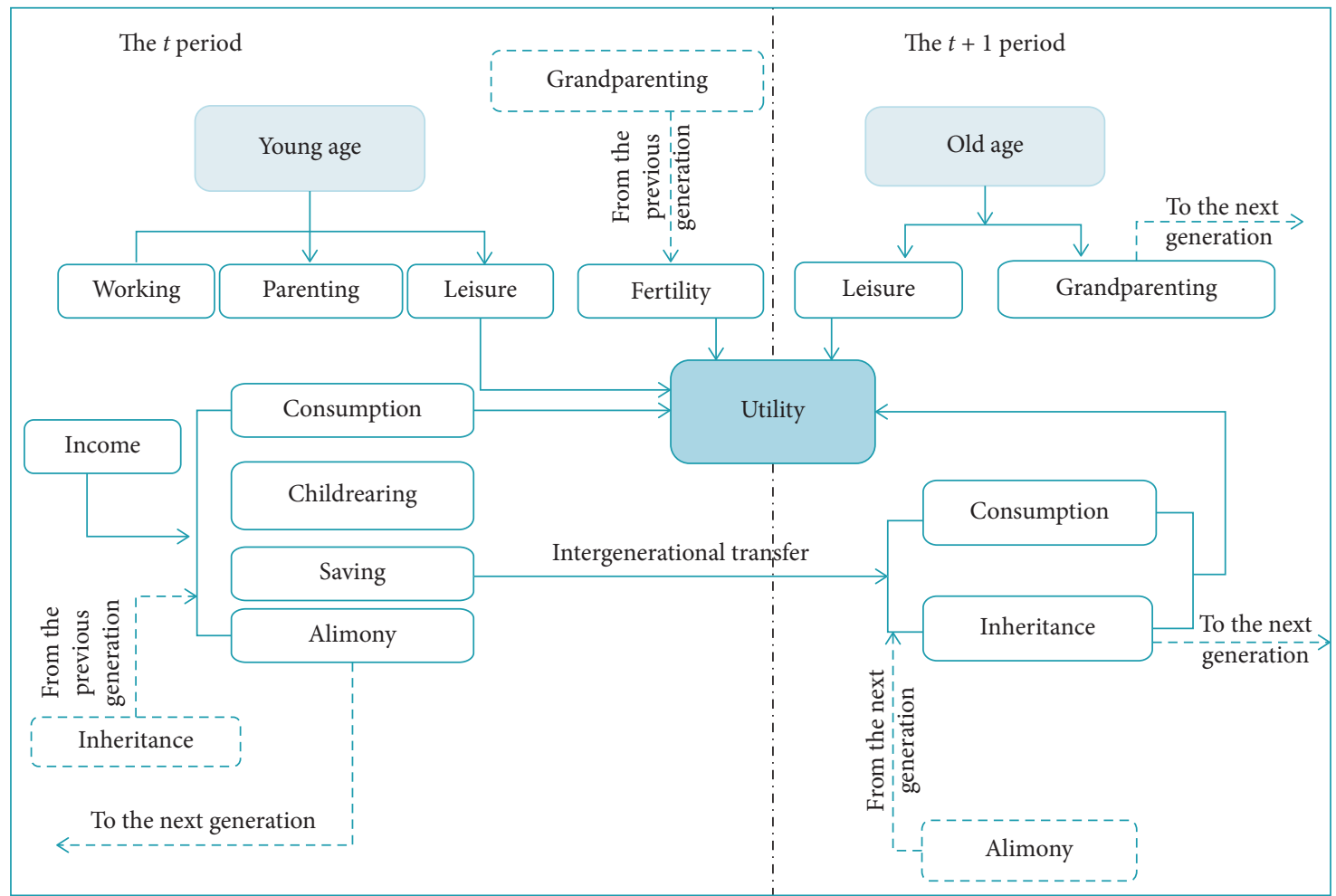

FIGURE 1: An overview of the structure of the developed OLG model for typical individuals. Intergenerational time and finical transfer, in the form of grandparenting, alimony, and inheritance, as well as intertemporal finical transfer, are considered.

$$
L_{t}=N_{t} l_{t}
$$

Suppose that the capital is fully depreciated at the end of each period; then, the capital stock of the next period equals the total savings of the current period multiplied by the interest rate of the next period:

$$
K_{t+1}=s_{t} N_{t} R_{t+1} \text {, }
$$

and with equations (9)-(11), we get the capital stock of the $t+1$ period.

$$
k_{t+1}=\frac{\left(s_{t} R_{t+1}\right)}{\left(n_{t} l_{t+1}^{e}\right)} .
$$

2.1.4. Model Optimization. Since the variables $c_{1, t}, c_{2, t+1}, h_{1, t}$, and $h_{2, t+1}$ are the functions of $l_{t}, s_{t}, n_{t}, z_{t+1}$, and $O_{2, t+1}$ (see equations (2)-(5)), essentially the utility (equation (1)) of the individual only depends on the decisions of $l_{t}, s_{t}, n_{t}, z_{t+1}$, and $\mathrm{O}_{2, t+1}$. For the purpose of maximum utility, we differentiate utility function with respect to $l_{t}, s_{t}, n_{t}, z_{t+1}$, and $O_{2, t+1}$ separately and get the first-order conditions. Moreover, suppose that the expectance of the birth number, labor time, and wage rate of young children is absolutely suitable to the actuality; then, $n_{t+1}^{e}=n_{t+1}, l_{t+1}^{e}=l_{t+1}$, and $w_{t+1}^{e}=w_{t+1}$. The first-order optimal conditions can be rewritten as a system of nonlinear dynamic equations.

$$
\begin{aligned}
& {\left[w_{t} l_{t}\left(1-\eta-\mu n_{t}\right)+\frac{O_{2, t}}{n_{t-1}}-s_{t}\right] \rho \beta R_{t+1}-\left(R_{t+1} s_{t}+w_{t+1} l_{t+1} \eta n_{t}-O_{2, t+1}\right)=0,} \\
& {\left[w_{t} l_{t}\left(1-\eta-\mu n_{t}\right)+\frac{O_{2, t}}{n_{t-1}}-s_{t}\right] \gamma-w_{t}\left(1-\eta-\mu n_{t}\right)\left[1-l_{t}-n_{t}\left(E-z_{t}\right)\right]=0,} \\
& \frac{\left(\rho \beta \eta w_{t+1} l_{t+1}\right)}{\left(R_{t+1} s_{t}+w_{t+1} l_{t+1} \eta n_{t}-O_{2, t+1}-\left(\left(\mu w_{t} l_{t}\right) /\left(w_{t} l_{t}\left(1-\eta-\mu n_{t}\right)+O_{2, t} / n_{t-1}-s_{t}\right)\right)\right)} \\
& +\frac{\theta}{\left(n_{t}-\gamma\left(E-z_{t}\right) /\left(1-l_{t}-n_{t}\left(E-z_{t}\right)\right)\right)}-\frac{\left(\beta \gamma z_{t+1} n_{t+1}\right)}{\left(\rho-n_{t+1} n_{t} z_{t+1}\right)}=0, \\
& \beta \gamma n_{t} n_{t+1}\left(R_{t+1} s_{t}+w_{t+1} l_{t+1} \eta n_{t}-O_{2, t+1}\right)-\rho \beta \eta w_{t+1} n_{t} n_{t+1}\left(\rho-n_{t+1} n_{t} z_{t+1}\right)=0,
\end{aligned}
$$




$$
\tau\left(R_{t+1} s_{t}+w_{t+1} l_{t+1} \eta n_{t}-O_{2, t+1}\right)-\rho \beta O_{2, t+1}=0 .
$$

Therefore, we obtain the DGE model which consists of an individual's maximum utility (equations (13)-(17)), firm's maximum profit (equations (7) and (8)), and market clearing (equation (12)). These eight equations indicate the dynamic process of the individual and firm making their decisions to get the maximum utility and profit under the condition of market clearing.

Since the model is an intertemporal dynamic process and the current period decisions are influenced by the previous period and the next period, we could not figure out the decision variables of an individual to make personal utility to the maximum. Therefore, we will estimate the steady-state values by means of numerical simulation in Section 2.3 to explore the effect of intergenerational childcare on the birth number as life expectancy increases.

2.2. The Econometric Model without considering Grandparental Childcare. In order to further explore the effect of intergenerational childcare on the number of births, we also build a new OLG model without considering intergenerational childcare variable for typical individuals. Compared to the OLG model introduced in Section 2.1, the utility function (equation (1)) and monetary constraints (equations (2) and (3)) at the young and old age remain unchanged, and the time related constraints are as follows:

$$
\begin{aligned}
h_{1, t} & =1-l_{t}-n_{t} E, \\
h_{2, t+1} & =\rho .
\end{aligned}
$$

Individuals make decisions about $l_{t}, s_{t}, n_{t}, O_{2, t+1}$ to maximize the utility (equation (1)) under the corresponding constraints. The constraints regarding firms and market clearing condition are also the same as those of the model with intergenerational childcare. Thus, the model can be solved with a method similar to that in Section 2.1.4.

2.3. Theoretical Analysis with Numerical Simulation. In this section, we conduct numerical simulation to identify the effect of intergenerational childcare.

2.3.1. Parameter Settings. Following the parameter settings in the previous studies $[17,18]$, we set $\beta=0.99^{3} 0, \gamma=0.8$, $\alpha=0.3, E=0.3, \theta=2$, and $A=1$. We also set the length of young age as 30 years, and the young age starts from 18 years. Suppose that the length of old age $\rho$ ranges from 0.7 to 2.0, which denotes the lifespan from 69 years to 108 years of age. We set that the proportion of the elderly parent's alimony to the total income is $20 \%$ and the proportion of expenditure to raise a child is $10 \%$. In China, the economic interactions between parents and grown-up children are very common and frequent. Since many old people are influenced by traditional ideas, many old individuals prefer to give their property to their children rather than cost the savings and alimony themselves. Therefore, we set the preferred coefficient to gift inheritance to children.

2.3.2. Estimation of the Steady State. The value of old-age length $(\rho)$ varies from 0.7 to 2 with the interval of 0.05 . We get the steady-state values of all variables by solving the eight equations of the DGE model using MATLAB software when fixing the value of $\rho$. With the 27 sets of steady-state values, we can simulate the variation trend of intergenerational childcare and the number of children (Figures 2 and 3 ). As shown in the figures, with the extension of lifespan, the degree of intergenerational childcare and the numbers of birth children increase accordingly.

2.3.3. Simulation Results. Firstly, as is shown in Figure 2(a), the time of intergenerational childcare increases with the extension of lifespan. The improvement of intergenerational childcare is mainly due to the increase of old-age length providing more time allocated to intergenerational childcare and leisure. Secondly, as is shown in Figure 3, the number of birth children in the model with intergenerational childcare is always larger than that in the model without intergenerational childcare, and the birth number of the model with intergenerational childcare increases with the extension of lifespan while the birth of number of model without intergenerational childcare decreases as lifespan becomes longer. The comparison of two models indicates that intergenerational childcare not only promotes the increasing of birth number but also helps maintain its positive trend as the increase of life expectancy. In addition, as is shown in Figure 3(b), the necessary parenting time from young parents decreases with the extension of old-age length in the two models. For the model without intergenerational childcare, the decrease of necessary parenting time is due to the decrease of birth number, while the individuals with intergenerational childcare pay less time to raise their children due to grandparents sharing the responsibility of raising children despite the increase of birth number. Therefore, intergenerational childcare not only improves the number of birth children but also relieves parenting stress to allow young individuals to allocate more time to labor supply and leisure.

\section{Empirical Analysis}

The DGE model in the previous section has theoretically proven the potential positive effect of grandparenting on the number of births. In this section, we further conduct empirical studies of the impact of intergenerational childcare on the birth of the second child with data from China.

3.1. Data. For the empirical study, we draw on the data from the China Migrants Dynamic Survey in 2016 (https://www. chinaldrk.org.cn/wjw/\#/home) (CMDS 2016), a large-scale 


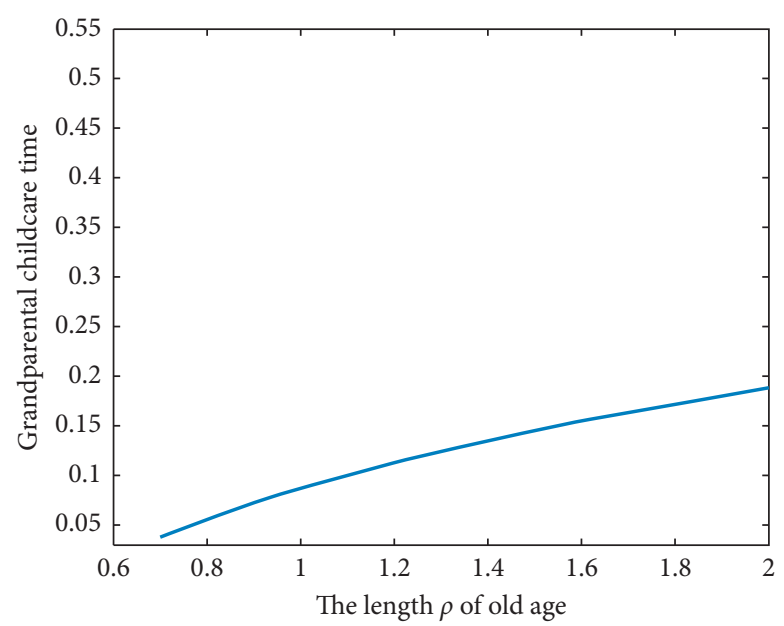

(a)

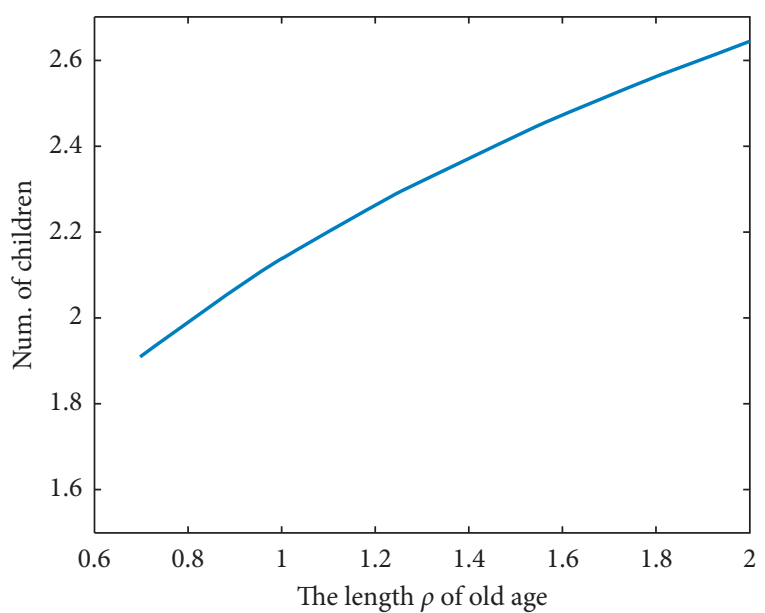

(b)

FIGURE 2: Simulation study of the DGE model with considering intergenerational childcare. (a) The association of length $\rho$ of old age with grandparental childcare time; (b) the association of length $\rho$ of old age with the number of children of their offspring.

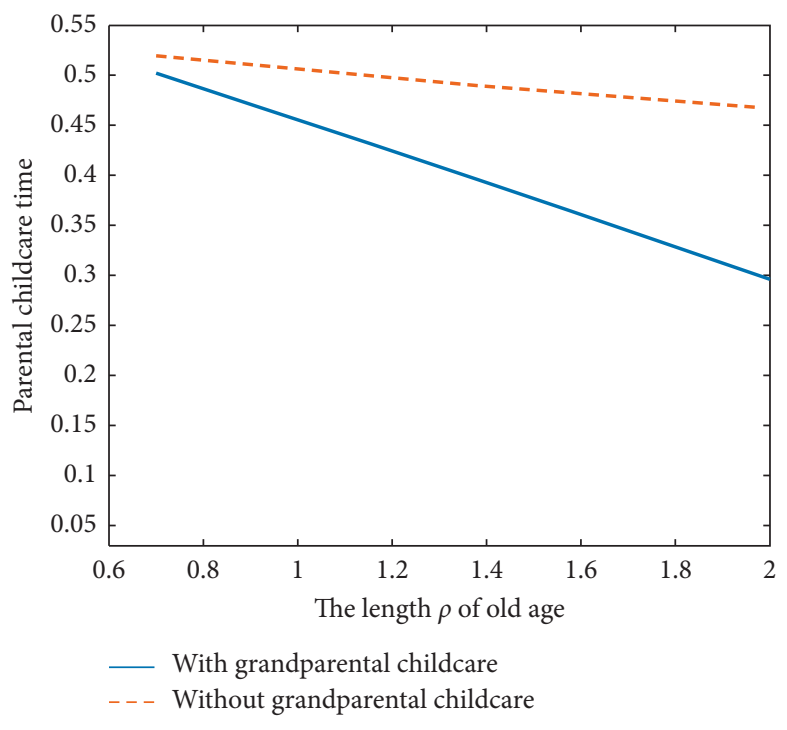

(a)

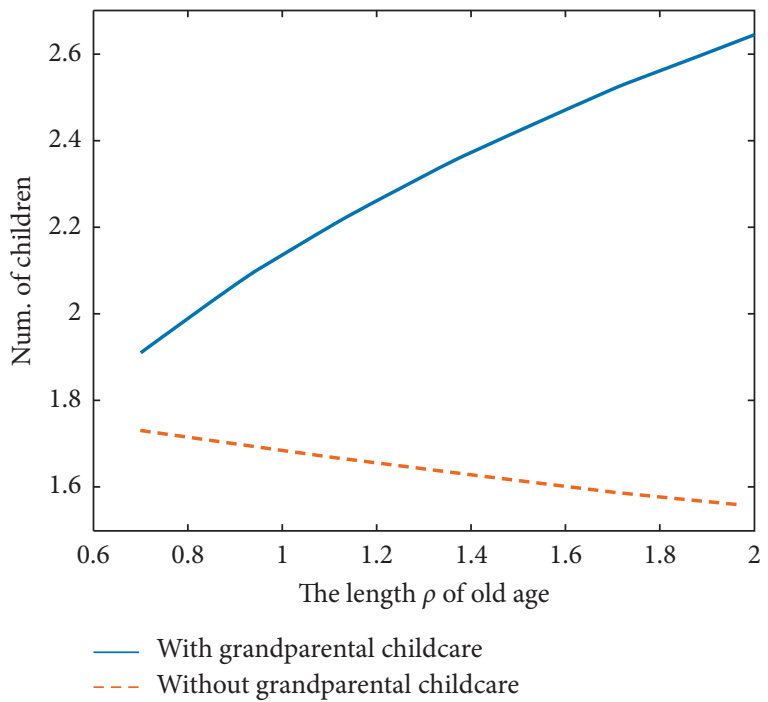

(b)

FIGURE 3: Simulation study of the DGE model with/without considering intergenerational childcare (i.e., grandparental childcare). (a) The association of length $\rho$ of old age with parental childcare time; (b) the association of length $\rho$ of old age with number of children of their offspring.

household survey of the internal-migrant population in China conducted by the National Health Commission of the People's Republic of China. The CMDS 2016 collected the information of 169,000 migrant respondents aged over 15 years in over 400 cities, providing an opportunity for researchers to study the demographic profiles and socioeconomic status of migrants and their marriage and bearing status nationwide. Significantly, the CMDS collected information about the primary-care provider for the first child, which is favorable to investigate the effect of grandparental childcare.

Since the data in CMDS 2016 were collected after the formal operation of the universal two-child policy, there are no policy barriers for the birth of the second child for almost all Chinese people. According to the 2018 Report on China's Migrant Population Development (National Health and Family Planning Commission 2018), the number of married women of childbearing age in the internal-migrant population makes up about a quarter of that all over China mainland. Moreover, more than $80 \%$ of the married migrants choose to migrate from one place to another with their spouses. Thus, the data used for our empirical study are representative and suitable for the investigation of the second birth.

To investigate the birth of the second child, we selected a subset of data from the CMDS 2016 based on five criteria: 
age, marital status, the number and age of children, and living with the partner. Specifically, we select those couples who were both under the age of 45 years at the time of the interview, already have given birth to at least one child, never experienced divorce, and migrated to the same place. Remarried couples were excluded because the number of stepchildren may already be more than two. Under the universal two-child policy in China, all married couples can have no more than two children. Accordingly, 76,946 cases meet these criteria.

Moreover, we excluded 52 respondents with the first child who died, 619 respondents with twins or multiple births, and 46 respondents with missing values for crucial variables. We further excluded 15,180 respondents with the first child who was over 18 years of age or under 2 years of age at the time of the interview. Note that the recommended interbirth interval (IBI) by the WTO is at least 24 months between pregnancies. An IBI of lower than 18 months is associated with an increased risk of preterm birth. Typically, Chinese couples usually begin to have enough time to choose whether to have a second child after their first child is 2 years old. By applying these selection criteria, we obtained a sample size of 61,049 .

3.1.1. Descriptive Statistics of the Data. Table 1 gives the variables used in the following regression analysis and the descriptive statistics of these variables. We use the binary variable of whether having the second birth as the explained variable and use both demographic and socioeconomic variables as the explanatory variables. More specifically, the used demographic variables include the age and ethnicity of the parents, the age and gender of the first child, and the primary care-provider for the first child; the socioeconomic variables consist of education level, family monthly income, settlement intention, and the type of household registration (also known as Hukou). The inclusion of household registration as explanatory variable is to account for the differences in fertility policy between registered rural residents and registered urban residents before 2016 in China. Moreover, the access to most social welfare and social services is tied with Hukou in China. As shown in Table 1, $83.3 \%$ of the migrant couples in the sample both hold rural Hukou, which indicates the massive migration of the labor force from rural to urban areas in China. In fact, rural-urban migration constitutes the largest share of migration, which is one of the main characters in domestic migrants in China.

As shown in Table 1, while in more than half (53.2\%) of the migrant families, the first child is jointly taken care of by their parents, the grandparents act as the primary-care provider for the first child in $23.3 \%$ of the migrant families, which is higher than childcare by mother. Moreover, the proportion of migrant couples with a second birth is up to $44.3 \%$, which is a relatively large proportion. Thus, we also report the descriptive statistics about two subgroups: households having one birth and households already having two births. For couples having two births, $26.7 \%$ of them entrust the grandparents to take care of the first child. In contrast, for couples that have only one child, this proportion is only $20.6 \%$. Thus, childcare support from grandparents is more common for families with more than one child in China.

From Table 1, we can also see that migrant couples with higher education levels tend to have fewer children. Compared to the group of parents having only one child, the parents having two births show a higher proportion of having rural Hukou and a lower proportion of taking care of the first child by themselves.

3.1.2. Determinants of Having Grandparental Childcare for the First Child. Our empirical study aims to identify the treatment effect of grandparental childcare for the first child on the second birth. We first identify possible determinants of having grandparental childcare for the first child with a basic regression model. Table 2 summarizes the logistic regression results, in which the binary treatment status (i.e., whether having grandparents to be the primary-care provider for the first child) was regressed on basic explanatory variables in the CMDS 2016. As shown in Table 2, the selected explanatory variables can provide a good estimation and also are jointly statistically significant $(p>0.000)$ with LR $\chi^{2}$ statistics $=14620.81$. The pseudo $R^{2}(0.22)$ also shows a good model fit. This logistic regression model is also employed as the propensity score model used in the following treatment effect estimation.

The results in Table 2 show that the migrating status of the child, labor participation of the parents, settlement intention, family monthly income, age and gender of the first child, and ages of parents are critical factors affecting having grandparents to be the primary-care provider for the first child. Especially, our results also show that leaving the child where the Hukou is registered is more likely to result in grandparental childcare.

\subsection{Treatment Effects of Grandparental Childcare on the Birth} of the Second Child. Given the nonexperimental observations in the CMDS, the estimation of the treatment effect of having grandparents as the primary-care provider for the first child is a challenging task because of the potential observable and unobservable biases. More specifically, in an observational study, due to the lack of randomization, statistical inferences without adjusting the self-selection bias (nonrandom assignment) usually include observed or unobserved effects of covariates. A difference in the treatment outcome between the treated and control groups may be caused by a factor that predicts treatment rather than the treatment itself. Thus, the main challenge is constructing the counterfactual outcome, that is, what would have happened to participants in the absence of grandparental childcare (i.e., the treatment).

To estimate the unobservable counterfactual outcomes, we adopt propensity score matching (PSM) [27], which employs information from a pool of untreated observations to identify what would have happened to the treated observations in the absence of the treatment. More specifically, PSM is a statistical matching technique that constructs an artificial control group by matching each treated observation 
TABLE 1: Descriptive statistics of the used sample, which is a subset of the CMDS2016. For variables with binary values, the mean indicates the proportion of the positive class.

\begin{tabular}{|c|c|c|c|c|c|c|c|c|}
\hline \multirow{3}{*}{ Type } & \multirow{3}{*}{ Variable } & \multirow{3}{*}{ Description } & \multirow{2}{*}{\multicolumn{2}{|c|}{$\begin{array}{l}\text { Full sample } \\
N=61,049\end{array}$}} & \multirow{2}{*}{\multicolumn{2}{|c|}{$\begin{array}{l}\text { Household } \\
\text { (two births) } \\
N=27,067\end{array}$}} & \multirow{2}{*}{\multicolumn{2}{|c|}{$\begin{array}{c}\text { Household (one } \\
\text { birth) } \\
N=33,982\end{array}$}} \\
\hline & & & & & & & & \\
\hline & & & Mean & S.D. & Mean & S.D. & Mean & S.D. \\
\hline \multirow[t]{6}{*}{ Explained } & Having the second birth & Yes & 0.443 & 0.497 & 1 & 0 & 0 & 0 \\
\hline & Age of the father & Continuous (years) & 34.494 & 5.102 & 35.261 & 4.875 & $33.882^{* * *}$ & 5.195 \\
\hline & Age of the mother & Continuous (years) & 32.680 & 5.098 & 33.445 & 4.922 & $32.071^{* * *}$ & 5.153 \\
\hline & Ethnicity of the parents & Both Hans & 0.903 & 0.296 & 0.885 & 0.319 & $0.918^{* * *}$ & 0.275 \\
\hline & Age of the first child & Continuous (years) & 8.770 & 4.372 & 10.255 & 4.115 & $7.588^{* * *}$ & 4.207 \\
\hline & Gender of the first child & Girl & 0.466 & 0.499 & 0.577 & 0.494 & $0.377^{* * *}$ & 0.485 \\
\hline \multirow[t]{6}{*}{ Demographic } & \multirow{6}{*}{ Primal-care provider for the first child } & Parents & 0.532 & 0.499 & 0.507 & 0.500 & $0.551^{* * *}$ & 0.497 \\
\hline & & Father & 0.007 & 0.086 & 0.006 & 0.078 & $0.008^{* * *}$ & 0.091 \\
\hline & & Mother & 0.196 & 0.397 & 0.186 & 0.006 & $0.203^{* * *}$ & 0.402 \\
\hline & & Grandparents & 0.233 & 0.423 & 0.267 & 0.442 & $0.206^{* * *}$ & 0.404 \\
\hline & & Other caretakers & 0.028 & 0.165 & 0.028 & 0.165 & 0.028 & 0.166 \\
\hline & & Nobody & 0.004 & 0.065 & 0.005 & 0.072 & $0.004^{* * *}$ & 0.060 \\
\hline \multirow{18}{*}{ Socioeconomic } & \multirow{5}{*}{ Education level of the father } & $\begin{array}{c}\text { Junior school and } \\
\text { below }\end{array}$ & 0.083 & 0.276 & 0.118 & 0.323 & $0.055^{* * *}$ & 0.228 \\
\hline & & Junior high school & 0.566 & 0.496 & 0.627 & 0.484 & $0.518^{* * *}$ & 0.500 \\
\hline & & Senior high school & 0.233 & 0.423 & 0.193 & 0.395 & $0.265^{* * *}$ & 0.441 \\
\hline & & College and above & 0.117 & 0.322 & 0.061 & 0.239 & $0.162^{* * *}$ & 0.369 \\
\hline & & $\begin{array}{c}\text { Junior school and } \\
\text { below }\end{array}$ & 0.118 & 0.322 & 0.173 & 0.378 & $0.074^{* * *}$ & 0.261 \\
\hline & \multirow[t]{3}{*}{ Education level of the mother } & Junior high school & 0.569 & 0.495 & 0.619 & 0.486 & $0.530^{* * *}$ & 0.499 \\
\hline & & Senior high school & 0.214 & 0.410 & 0.162 & 0.369 & $0.255^{* * *}$ & 0.436 \\
\hline & & College and above & 0.099 & 0.299 & 0.046 & 0.209 & $0.142^{* * *}$ & 0.349 \\
\hline & \multirow[t]{2}{*}{ Family monthly income } & Continuous (in log) & 8.763 & 0.536 & 8.742 & 0.556 & $8.779^{* * *}$ & 0.519 \\
\hline & & Settle down & 0.622 & 0.485 & 0.597 & 0.491 & $0.642^{* * *}$ & 0.480 \\
\hline & \multirow{3}{*}{ Settlement intention } & Return home & 0.045 & 0.207 & 0.047 & 0.211 & $0.043^{* *}$ & 0.203 \\
\hline & & Go to other places & 0.028 & 0.164 & 0.028 & 0.164 & 0.028 & 0.164 \\
\hline & & Uncertain & 0.306 & 0.461 & 0.328 & 0.470 & $0.288^{* * *}$ & 0.453 \\
\hline & \multirow{3}{*}{$\begin{array}{l}\text { Household registration (a.k.a Hukou) of the } \\
\text { parents }\end{array}$} & Both rural Hukous & 0.833 & 0.373 & 0.891 & 0.311 & $0.786^{* * *}$ & 0.410 \\
\hline & & Different Hukou types & 0.075 & 0.264 & 0.053 & 0.224 & $0.093^{* * *}$ & 0.290 \\
\hline & & Both urban Hukous & 0.092 & 0.289 & 0.055 & 0.229 & $0.121^{* * *}$ & 0.326 \\
\hline & The child migrates with their parents & Yes & 0.512 & 0.500 & 0.540 & 0.498 & $0.490^{* * *}$ & 0.500 \\
\hline & The respondent participates in labor force & Yes & 0.848 & 0.359 & 0.835 & 0.371 & $0.858^{* * *}$ & 0.350 \\
\hline
\end{tabular}

S.D.: standard deviation. A hypothesis test is conducted to identify the difference between the means of the two-birth household group and one-birth household group. ${ }^{*},{ }^{* *}$, and ${ }^{* * *}$ denote significance levels of $10 \%, 5 \%$, and $1 \%$, respectively.

with an untreated observation of similar characteristics. The effects of the treatment can be obtained by comparing the outcomes of the participants and observationally similar nonparticipants. Given a subject and a treatment (i.e., having grandparental childcare for the first child), each subject $i$ receives only one of the active treatment and control treatment and has a pair of potential outcomes, i.e., the outcome $Y_{i}^{1}$ under active treatment (actual) and the outcome $Y_{i}^{0}$ under control treatment (counterfactual). Treatment $D_{i}$ is an indicator variable, and $D_{i}=1$ for treated observations and $D_{i}=0$ for control observations. Thus, with $D_{i}$, the outcome can be defined as

$$
Y_{i}=D_{i} Y_{i}^{1}+\left(1-D_{i}\right) Y_{i}^{0} .
$$

When the first child in a family is mainly taken care of by the grandparents, the potential outcome $Y^{0}$ in the absence of grandparental childcare is not observed. At the population level, the average treatment effect for the treated (ATT) is defined as

$$
\mathrm{ATT}=\sum_{i} E\left(Y_{i}^{1} \mid D_{i}=1\right)-E\left(Y_{i}^{0} \mid D_{i}=1\right)
$$

where the second term is a counterfactual term and the ATT can be estimated using PSM. Firstly, the propensity scores are estimated with logistic regression results in Table 3; secondly, observations from treated and control groups based on their propensity scores are matched to achieve balance between groups. Finally, the outcomes between the treated and control observations are compared.

In our experiments, PSM is performed on the explanatory variables described in the logistic model shown in Table 2. The regression results indicate that the used explanatory variables are important in predicting the possibility of having grandparental childcare for the child. Before estimating the treatment effects of grandparental childcare, we tested the common support condition and balancing property [27], which are the crucial assumptions for the establishment of PSM. Figure 4 shows the sufficient overlap 
TABLE 2: The propensity score model: logistic regression results of factors affecting having grandparents as the primary-care provider for the first child.

\begin{tabular}{|c|c|c|c|c|c|}
\hline Explanatory variables & Coef. & S.E. & $z$ & $p>|z|$ & [95\% conf. Interval] \\
\hline Age of the father & -0.047 & 0.004 & -11.04 & 0.001 & {$[-0.055,-0.039]$} \\
\hline Age of the mother & -0.037 & 0.004 & -8.22 & 0.001 & {$[-0.046,-0.028]$} \\
\hline \multicolumn{6}{|l|}{ Ethnicity of the parents } \\
\hline (i) Both Hans & 0.287 & 0.040 & 7.10 & 0.001 & {$[0.208,0.366]$} \\
\hline Age of the first child & 0.110 & 0.012 & 8.94 & 0.001 & {$[0.086,0.135]$} \\
\hline Square of the age of the first child & 0.001 & 0.001 & 0.14 & 0.886 & {$[-0.001,0.001]$} \\
\hline The first child is a girl & 0.106 & 0.0219 & 4.81 & 0.001 & {$[0.063,0.149]$} \\
\hline \multicolumn{6}{|l|}{$\begin{array}{l}\text { Education level of the father } \\
\text { (Junior school and below, ref.) }\end{array}$} \\
\hline (i) Junior high school & 0.112 & 0.047 & 2.38 & 0.017 & {$[0.020,0.204]$} \\
\hline (ii) Senior high school & 0.068 & 0.054 & 1.26 & 0.209 & {$[-0.038,0.173]$} \\
\hline (iii) College and above & -0.025 & 0.068 & -0.37 & 0.713 & {$[-0.158,0.108]$} \\
\hline \multicolumn{6}{|l|}{$\begin{array}{l}\text { Education level of the mother } \\
\text { (Junior school and below, ref.) }\end{array}$} \\
\hline (i) Junior high school & 0.010 & 0.041 & 0.24 & 0.814 & {$[-0.070,0.089]$} \\
\hline (ii) Senior high school & -0.141 & 0.050 & -2.84 & 0.005 & {$[-0.238,-0.044]$} \\
\hline (iii) College and above & -0.148 & 0.067 & -2.22 & 0.027 & {$[-0.279,-0.017]$} \\
\hline Family monthly income (in log) & 0.185 & 0.022 & 8.44 & 0.001 & {$[0.142,0.228]$} \\
\hline \multicolumn{6}{|l|}{$\begin{array}{l}\text { Settlement intention } \\
\text { (Settle down, ref.) }\end{array}$} \\
\hline (i) Return home & 1.093 & 0.049 & 22.53 & 0.001 & {$[0.998,1.188]$} \\
\hline (ii) Go to other places & 0.727 & 0.063 & 11.55 & 0.001 & {$[0.604,0.850]$} \\
\hline (iii) Uncertain & 0.797 & 0.024 & 33.06 & 0.001 & {$[0.750,0.844]$} \\
\hline \multicolumn{6}{|l|}{$\begin{array}{l}\text { Hukou of the parents } \\
\text { (Both rural Hukous, ref.) }\end{array}$} \\
\hline (i) Different Hukou types & -0.131 & 0.045 & -2.93 & 0.003 & {$[-0.218,-0.043]$} \\
\hline (ii) Both urban Hukous & -0.166 & 0.044 & -3.80 & 0.001 & {$[-0.252,-0.080]$} \\
\hline The respondent participates in labor force & 0.927 & 0.037 & 24.84 & 0.001 & {$[0.854,1.001]$} \\
\hline The child migrates with the parents & -2.402 & 0.027 & -89.13 & 0.001 & {$[-2.455,-2.350]$} \\
\hline Sample size $(N)$ & 61,049 & & & & \\
\hline$-2 \mathrm{LL}$ & 25818.020 & & & & \\
\hline Pseudo $R^{2}$ & 0.221 & & & & \\
\hline $\operatorname{LR} \chi^{2}(20)$ & 14620.810 & & & & \\
\hline$p>\chi^{2}(20)$ & 0.001 & & & & \\
\hline
\end{tabular}

S.E.: standard errors; LL: log likelihood.

in the density distributions of propensity scores for the treated and control groups. As for matching, we tested three popular matching methods, i.e., nearest neighbor matching (NNM), radius matching ( $\mathrm{RM})$, and kernel matching (KM). After matching, we have conducted a $t$-test of the balance between groups. As shown in Table 3, after matching, the absolute of the bias for all variables is significantly reduced, and there are smaller differences between the treated and control groups for almost all variables, implying good matching quality. Therefore, the common support condition and the balancing property are fulfilled.

Table 4 presents the estimated ATT after controlling selfselection biases with PSM, revealing the presence of positive and statistically significant effects of intergeneration childcare on the birth of the second child, which further confirms the findings in our theoretical analysis. The PSM results in Table 4 also show that the ATT values estimated with all the three (NNM, RM, and KM) algorithms show similar positive effects, which indicates that results are independent of the matching algorithms used.

3.3. Sensitivity Analysis. To test the robustness of the matching estimators of PSM against potential hidden bias attributed to unobserved variables, we follow Rosenbaum's procedure [29] to conduct sensitivity analysis. Table 5 presents the results of the $p$ value of Mantel and Haenszel (MH) test statistic [30] for the ATT while setting the level of hidden bias to certain levels $\Gamma$. In an observational study, by comparing the Rosenbaum bounds on grandparental childcare treatment effects at different levels of hidden bias, we can identify the critical level of $\Gamma$ at which our conclusion of positive treatment effect can be questioned. Concretely, the critical level of $\Gamma$ lies between 1.2 and 1.25 by setting a conventional $p$ value 
TABLE 3: Matching quality test: balancing property.

\begin{tabular}{|c|c|c|c|c|c|c|c|}
\hline \multirow{2}{*}{ Explanatory variables } & \multirow{2}{*}{ Matching } & \multicolumn{2}{|c|}{ Mean } & \multicolumn{2}{|c|}{ Bias (\%) } & \multicolumn{2}{|c|}{$t$-test } \\
\hline & & Treated & Controls & Bias & Reduct. & $t$ & $p>|t|$ \\
\hline \multirow{2}{*}{ Age of the father } & Before & 34.026 & 34.635 & -11.9 & - & -12.48 & 0.001 \\
\hline & After & 34.026 & 34.051 & -0.5 & 96.0 & -0.40 & 0.692 \\
\hline \multirow{2}{*}{ Age of the mother } & Before & 32.291 & 32.798 & -9.9 & - & -10.40 & 0.001 \\
\hline & After & 32.291 & 32.299 & -0.2 & 98.3 & -0.14 & 0.889 \\
\hline \multirow{2}{*}{ Ethnicity of the parents } & Before & 0.923 & 0.897 & 8.9 & - & 9.03 & 0.001 \\
\hline & After & 0.923 & 0.922 & 0.1 & 98.3 & 0.13 & 0.894 \\
\hline \multirow{2}{*}{ Age of the first child } & Before & 8.912 & 8.727 & 4.2 & - & 4.42 & 0.001 \\
\hline & After & 8.912 & 8.961 & -1.1 & 73.8 & -0.91 & 0.364 \\
\hline \multirow{2}{*}{ Square of the age of the first child } & Before & 99.386 & 95.015 & 5.1 & - & 5.36 & 0.001 \\
\hline & After & 99.386 & 100.73 & -1.6 & 69.1 & -1.28 & 0.199 \\
\hline \multicolumn{8}{|l|}{$\begin{array}{l}\text { Gender of the first child } \\
\text { (Boy, ref.) }\end{array}$} \\
\hline \multirow{2}{*}{ (i) Girl } & Before & 0.477 & 0.462 & 2.9 & - & 3.04 & 0.002 \\
\hline & After & 0.477 & 0.483 & -1.3 & 55.4 & -1.09 & 0.275 \\
\hline \multicolumn{8}{|l|}{$\begin{array}{l}\text { Education level of the father } \\
\text { (Junior school and below, ref.) }\end{array}$} \\
\hline \multirow{2}{*}{ (i) Junior high school } & Before & 0.604 & 0.555 & 10.0 & - & 10.41 & 0.001 \\
\hline & After & 0.604 & 0.605 & -0.2 & 97.9 & -0.18 & 0.856 \\
\hline \multirow{2}{*}{ (ii) Senior high school } & Before & 0.222 & 0.237 & -3.4 & - & -3.56 & 0.001 \\
\hline & After & 0.222 & 0.220 & 0.5 & 86.4 & 0.40 & 0.689 \\
\hline \multirow{2}{*}{ (iii) College and above } & Before & 0.092 & 0.125 & -10.6 & - & -10.71 & 0.001 \\
\hline & After & 0.092 & 0.092 & 0.1 & 99.1 & 0.08 & 0.935 \\
\hline \multicolumn{8}{|l|}{$\begin{array}{l}\text { Education level of the mother } \\
\text { (Junior school and below, ref.) }\end{array}$} \\
\hline \multirow{2}{*}{ (i) Junior high school } & Before & 0.610 & 0.557 & 10.8 & - & 11.22 & 0.001 \\
\hline & After & 0.610 & 0.604 & 1.3 & 88.1 & 1.09 & 0.274 \\
\hline \multirow{2}{*}{ (ii) Senior high school } & Before & 0.192 & 0.220 & -7.2 & - & -7.37 & 0.001 \\
\hline & After & 0.192 & 0.192 & -0.1 & 98.1 & -0.12 & 0.904 \\
\hline \multirow{2}{*}{ (iii) College and above } & Before & 0.078 & 0.106 & -9.5 & - & -9.62 & 0.001 \\
\hline & After & 0.078 & 0.077 & 0.4 & 95.4 & 0.40 & 0.690 \\
\hline \multirow{2}{*}{ Family monthly income (in log) } & Before & 8.818 & 8.746 & 13.9 & - & 14.03 & 0.001 \\
\hline & After & 8.818 & 8.825 & -1.3 & 90.7 & -1.08 & 0.280 \\
\hline \multicolumn{8}{|l|}{$\begin{array}{l}\text { Settlement intention } \\
\text { (Settle down, ref.) }\end{array}$} \\
\hline & Before & 0.077 & 0.035 & 18.6 & - & 21.58 & 0.001 \\
\hline (i) Return home & After & 0.077 & 0.072 & 2.2 & 88.4 & 1.58 & 0.114 \\
\hline & Before & 0.036 & 0.025 & 6.1 & - & 6.72 & 0.001 \\
\hline (ii) Go to other places & After & 0.036 & 0.038 & -1.4 & 78.0 & -1.04 & 0.299 \\
\hline & Before & 0.406 & 0.276 & 27.7 & - & 29.71 & 0.001 \\
\hline (iii) Uncertain & After & 0.406 & 0.415 & -1.9 & 93.1 & -1.53 & 0.126 \\
\hline $\begin{array}{l}\text { Hukou of the parents } \\
\text { (Both rural Hukou, ref.) }\end{array}$ & & & & & & & \\
\hline & Before & 0.062 & 0.079 & -6.5 & - & -6.64 & 0.001 \\
\hline (i) Different Hukou types & After & 0.062 & 0.062 & 0.1 & 98.3 & 0.10 & 0.922 \\
\hline & Before & 0.073 & 0.097 & -8.7 & - & -8.75 & 0.001 \\
\hline (ii) Both urban Huhous & After & 0.073 & 0.073 & 0.2 & 97.4 & 0.21 & 0.837 \\
\hline The resnondent narticinates in labor force & Before & 0.924 & 0.824 & 30.3 & - & 29.06 & 0.001 \\
\hline The respondent participates in labor force & After & 0.924 & 0.922 & 0.5 & 98.2 & 0.56 & 0.578 \\
\hline & Before & 0.141 & 0.625 & -114.6 & - & -110.60 & 0.001 \\
\hline The child migrates with the par & After & 0.141 & 0.145 & -0.8 & 99.3 & -0.78 & 0.436 \\
\hline
\end{tabular}

of 0.05. This implies that, to render the treatment effect estimates statistically insignificant at a significance level of 0.05 , the log odds ratio would have to change by $25 \%$. In other words, our treatment effect estimation is relatively robust to potential moderate hidden biases from unobserved variables.
3.4. Subgroup Analysis. To investigate possible heterogeneous results in subsets of respondents, we estimate treatment effects in different subgroups. We first investigate the treatment effects of grandparental childcare for groups of respondents with different labor-participation statuses, i.e., working and nonworking. It is noteworthy that the CMDS 


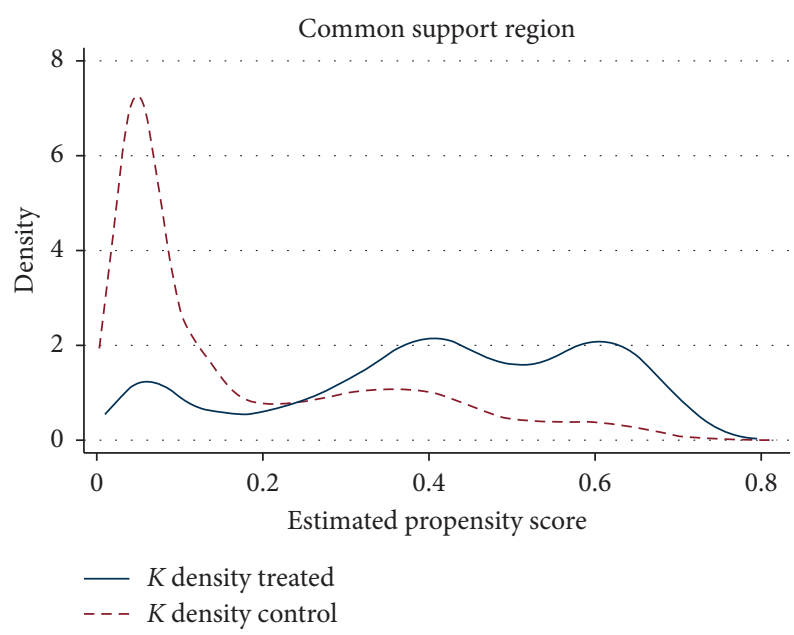

FIgURE 4: Density distribution of propensity scores for the treated and control groups.

TABle 4: Propensity score matching results: average treatment effect of grandparenting on the birth of the second child.

\begin{tabular}{|c|c|c|c|c|c|}
\hline & \multicolumn{2}{|c|}{ Mean } & \multirow{2}{*}{$\mathrm{ATT}$} & \multirow{2}{*}{ S.E. } & \multirow{2}{*}{ T-stat } \\
\hline & Treated & Controls & & & \\
\hline Sample size & 14,213 & 46,836 & - & - & - \\
\hline Before matching & 0.509 & 0.424 & 0.085 & 0.005 & 17.93 \\
\hline \multicolumn{6}{|l|}{ After matching } \\
\hline (i) NNM & 0.509 & 0.455 & 0.054 & 0.008 & 6.89 \\
\hline (ii) $\mathrm{RM}$ & 0.509 & 0.453 & 0.056 & 0.006 & 9.65 \\
\hline (iii) $\mathrm{KM}$ & 0.509 & 0.453 & 0.056 & 0.006 & 9.59 \\
\hline
\end{tabular}

ATT: average treatment effect on the treated; S.E.: standard errors.

TABLE 5: Sensitivity to unobserved biases: Rosenbaum bounds for grandparental childcare treatment effects.

\begin{tabular}{lcc}
\hline Gamma $\Gamma$ & $p_{\text {mh+ }}$ & $p_{\text {mh- }}$ \\
\hline 1.00 & $<0.0001$ & $<0.0001$ \\
1.05 & $<0.0001$ & $<0.0001$ \\
1.10 & $<0.0001$ & $<0.0001$ \\
1.15 & 0.0002 & $<0.0001$ \\
1.20 & 0.037 & $<0.0001$ \\
1.25 & 0.454 & $<0.0001$ \\
1.30 & 0.932 & $<0.0001$ \\
1.35 & 0.999 & $<0.0001$ \\
1.40 & 0.999 & $<0.0001$ \\
1.45 & 1.000 & $<0.0001$ \\
1.50 & 1.000 & $<0.0001$ \\
\hline
\end{tabular}

$\Gamma: \log$ odds of differential assignment due to unobserved factors; $p_{\mathrm{mh}+}$ : upper bound significance level (assumption: overestimation of treatment effect); $p_{\mathrm{mh}-}$ : lower bound significance level (assumption: underestimation of treatment effect).

TABLe 6: Descriptive statistics of female respondents and male respondents given different labor-participation statuses.

\begin{tabular}{|c|c|c|c|c|}
\hline & \multicolumn{2}{|c|}{ Female respondents } & \multicolumn{2}{|c|}{ Male respondents } \\
\hline & Working & Nonworking & Working & Nonworking \\
\hline Sample size & $21,905(65.5 \%)$ & $7,564(34.5 \%)$ & $29,839(94.2 \%)$ & $1,741(5.8 \%)$ \\
\hline Primal-care provider of the first child & Percentage (\%) & Percentage (\%) & Percentage (\%) & Percentage (\%) \\
\hline (i) Parents & 55.2 & 44.9 & 53.7 & 56.1 \\
\hline (ii) Father & 0.7 & 0.6 & 0.6 & 3.3 \\
\hline (iii) Mother & 11.9 & 41.9 & 19.5 & 20.8 \\
\hline (iv) Grandparents & 28.3 & 10.7 & 23.2 & 15.8 \\
\hline (v) Other caretakers & 3.5 & 1.7 & 2.6 & 2.9 \\
\hline (vi) Nobody & 0.4 & 0.2 & 0.4 & 1.1 \\
\hline Having the second birth & 41.9 & 48.9 & 45.0 & 44.1 \\
\hline
\end{tabular}


TABLE 7: ATT estimates for subgroups of women respondents: the treatment effects of having grandparents as the primary-care provider for the first child on having the second birth.

\begin{tabular}{lccccrr}
\hline \multirow{2}{*}{ Subgroups } & Sample size & Treated & Mean & ATT & SE & T-stat \\
& & 0.489 & 0.410 & 0.079 & 0.012 \\
Working & 21,905 & 0.597 & 0.549 & 0.111 & 0.45 \\
Nonworking & 7,564 & & & 0.027 & 4.06 \\
\hline
\end{tabular}

NNM is used as the matching method.

TABLE 8: ATT estimates for subgroups of couples: the treatment effect of having grandparents as the primary-care provider for the first child on having the second birth.

\begin{tabular}{lcccrrr}
\hline Subgroups of couples & \multirow{2}{*}{ Sample size } & Mean & ATT & SE & T-stat \\
\hline Both rural Hukou & 50,845 & 0.535 & 0.489 & 0.046 & 0.009 \\
At least one urban Hukou & 10,195 & 0.339 & 0.293 & 0.045 & 0.018 \\
\hline
\end{tabular}

NNM is used as the matching method.

2016 just collected the working information about the respondents, who may be female or male. Table 6 provides the descriptive statistics of female respondents and male respondents in our sample given different labor-participation status. While $65.5 \%$ of female respondents participate labor force, this proportion is over $94 \%$ for male respondents. Moreover, less than $4 \%$ of fathers act as the primary-care provider for the first child. Thus, we focus on the estimation of the treatment effect of grandparental childcare for female respondents. Table 7 summaries the effect of having grandparental childcare for the first child on the second birth given the different labor-participation status for female respondents. These results suggest that having grandparental childcare for the first child has a positive and significant impact on having the second birth. This boosting impact for the nonworking group is higher than for the working group.

Since rural-urban migration is one of the main characters in domestic migrants in China and has always been the largest share of migration, we further investigate the treatment effects for subgroups of different Hukou types: the couples both with rural Hukou and the couples with at least one urban Hukou. The PSM analysis illustrated in Table 8 shows that the treatment effects are positive in similar levels for subgroups of different Hukou types.

\section{Conclusions}

In this paper, we investigated the effects of intergeneration childcare on the birth of the second child in China with both theoretical and empirical analysis. Specifically, we have developed a DGE model calibrated to match some stylized facts of China's population. The theoretical analysis with numerical simulation has shown that, with the increase of life expectancy, hours that can be invested in grandparenting and the number of births will also increase; grandparenting is an important factor that can not only boost the fertility level but also help maintain its positive trend. Drawing on the internal-migrant data of the CMDS 2016, we conducted PSM analysis with controlling self-selection biases to estimate the treatment effect on the treated, which shows that intergeneration childcare has a statistically significant and positive effect on the birth of the second child. As a complement to the PSM estimation, we conducted sensitivity analysis based on Rosenbaum bounds, which indicates the relative robustness of our treatment estimates to moderate hidden biases attributed to unobservable variables. We also estimated treatment effects on different subgroups, i.e., the working and nonworking female respondents, and the couple groups of different Hukou types. The results show that having grandparental childcare for the first child has positive effects on all these subgroups. The limitation of this study is that we did not consider the household formation and intrahousehold decision-making process [31] for childcare due to the CMDS data lacking sufficient information, e.g., age, gender, health, labor force participation of the grandparents, the labour force participation of the respondent's spouse, and so on.

Findings from our analysis indicate that family arrangements about childcare have nontrivial macroeconomic effects. Given the limited actual effect [32] of the universal two-child policy in China, we argue that a comprehensive policy package is needed to boost the fertility rate. Especially, the policymakers should move faster to develop various types of childcare services and strengthen policy supports for promoting the sustainable and healthy development of childcare industry, since time and financial concerns are primary reasons making couples of reproductive ages hesitate to have a second child. Despite the obvious expansion of childcare facilities since 2010 [33], China still faces a shortage of childcare services. In the current stage, grandparenting, which has been proven in this study to have statistically significant and positive effects on the birth of the second child, is a sound and economic childcare arrangement to fill the parenting gap in a dual-earner family, especially when grandparents are retired/nonworking and in good health.

The provision of childcare by grandparents is a form of downward intergenerational time transfer with emotional 
involvement. However, this informal child care arrangement still faces many challenges in many families. Specifically, (1) there is usually an obvious gap in the type of child-rearing between the grandparents and the parents, and the intensive parenting style followed by young couples is typically challenging to grandparents; (2) grandparents also face pressure to balance their own family and the extent of involvement in grandparenting, especially when their partners are still working; (3) despite the positive effect on fertility increase, provision of intense care to grandchildren may also have an adverse impact on grandparents' well-being (China's State Council, 2010; [34]) due to the reduced leisure time and social connections; (4) for a migrant household where the parents leave home as migrant workers, there are more challenges for grandparenting depending on the living arrangements. When the grandparents migrate with their offspring, they usually cannot live with their spouse together and have to adapt themselves to a new environment, which will affect the willingness of grandparental childcare. When the parents left behind their children with grandparents, there have been many challenging issues that have become a rising concern recently; and (5) the contribution of grandparents needs better recognition by their offspring and the society.

Currently, the role of grandparents and the stainability of grandparental childcare are still less visible on the population policy agenda of policymakers. More efforts by the government, families, and the community, such as subsidizing grandparent childcare, supporting early childhood development, and improving the well-being of grandparents that involve in childcare, should be made to support family life and ensure this informal childcare arrangement goes on wheels.

\section{Data Availability}

The data used to support the findings of this study are available at https://www.chinaldrk.org.cn/wjw/\\#/home.

\section{Conflicts of Interest}

The authors declare no conflicts of interest.

\section{Acknowledgments}

This research was partially funded by the National Nature Science Foundation of China (No. 71973049) and the fund of Huaqiao University (No. ZQN-PY411).

\section{References}

[1] National Bureau of Statistics, China Statistical Yearbook, China Statistics Press, Beijing, China, 2020.

[2] J. Wang, Z. Ma, and L. Jiarui, "Rethinking China's actual and desired fertility: now and future," Population Research, vol. 43, pp. 32-43, 2019.

[3] J. Yang, "Research on migrants' fertility intention of the second child," Chinese Journal of Population Science, pp. 72-82, 2018.
[4] Y. Zhang, Research on the Willingness to Birth the Second Child and Cost-Benefit Analysis, China Youth Study, vol. 255, pp. 66-73, 2017.

[5] J. Van Bavel and J. Różańska-Putek, "Second birth rates across Europe: interactions between women's level of education and child care enrolment," Vienna Yearbook of Population Research, vol. 8, pp. 107-138, 2010.

[6] L. Ma, "Female labour force participation and second birth rates in South Korea," Journal of Population Research, vol. 33, no. 2, pp. 173-195, 2016.

[7] P.-C. Ko and K. Hank, "Grandparents caring for grandchildren in China and Korea: findings from CHARLS and KLoSA," The Journals of Gerontology Series B: Psychological Sciences and Social Sciences, vol. 69, no. 4, pp. 646-651, 2014.

[8] Q. Sun and H. Zhang, "The situation and influencing factors of Chinese older people taking care of their grandchildren," Population \& Economics, vol. 199, pp. 70-77, 2013.

[9] C. Duan, L. Lv, J. Guo, and Z. Wang, "Survival and development of left-behind children in rural China: based on the analysis of sixth census data," Population Journal, vol. 35, pp. 37-49, 2013.

[10] H. Lu, J. Yu, and Y. Du, "The influence of older parents' caregiving activities on labor supply of adult children: a study based on CFPS," Journal of Finance and Economics, vol. 43, no. 12, pp. 4-16, 2017.

[11] C. Ho, "Grandchild care, intergenerational transfers, and grandparents' labor supply," Review of Economics of the Household, vol. 13, pp. 359-384, 2013.

[12] J. Compton and R. A. Pollak, "Family proximity, childcare, and women's labor force attachment," Journal of Urban Economics, vol. 79, pp. 72-90, 2014.

[13] R. Dunifon and A. Bajracharya, "The role of grandparents in the lives of youth," Journal of Family Issues, vol. 33, no. 9, pp. 1168-1194, 2012.

[14] G. Zamarro, "Family labor participation and child care decisions: the role of grannies," SERIEs, vol. 11, no. 3, pp. 287-312, 2020.

[15] D. Cox, "Motives for private income transfers," Journal of Political Economy, vol. 95, no. 3, pp. 508-546, 1987.

[16] B. Arpino and V. Bordone, "Does grandparenting pay off? the effect of child care on grandparents' cognitive functioning," Journal of Marriage and Family, vol. 76, no. 2, pp. 337-351, 2014.

[17] L. Fanti and L. Gori, "An OLG model of growth with longevity: when grandparents take care of grandchildren," Portuguese Economic Journal, vol. 13, no. 1, pp. 39-51, 2014.

[18] Y. Wang, "The effects of population ageing on macro-economy-based on the inter generational dependency mechanism," Population and Development, vol. 22, pp. 13-23, 2016.

[19] P. Zhou, Delaying Retirement, Intergenerational Support and Fertility in China, The World of Survey and Research, vol. 281, pp. 6-10, 2017.

[20] A. Tanskanen and A. Rotkirch, "The impact of grandparental investment on mothers' fertility intentions in four European countries,” Demographic Research, vol. 31, pp. 1-26, 2014.

[21] A. Aassve, E. Meroni, and C. Pronzato, "Grandparenting and childbearing in the extended family," European Journal of Population/Revue Européenne de Démographie, vol. 28, no. 4, pp. 499-518, 2012.

[22] R. Kaptijn, F. Thomese, T. G. Van Tilburg, and A. C. Liefbroer, "How grandparents matter," Human Nature, vol. 21, no. 4, pp. 393-405, 2010.

[23] D. Waynforth, "Grandparental investment and reproductive decisions in the longitudinal 1970 British cohort 
study," Proceedings of the Royal Society B: Biological Sciences, vol. 279, pp. 1155-1160, 2012.

[24] S.-Y. Yoon, "The influence of a supportive environment for families on women's fertility intentions and behavior in South Korea," Demographic Research, vol. 36, pp. 227-254, 2017.

[25] Y. Jin, M. Zhao, and J. Song, "Parental influence on women's second-birth plan in urban China," Population Research, vol. 42, pp. 19-31, 2018.

[26] J. Wang and X. Yang, "A study of the division of family care and the willingness to have the second child in the process of urbanization," Journal of Public Administration, vol. 10, pp. 140-155, 2017.

[27] G. W. Imbens, "Nonparametric estimation of average treatment effects under exogeneity: a review," Review of Economics and Statistics, vol. 86, no. 1, pp. 4-29, 2004.

[28] P. R. Rosenbaum and D. B. Rubin, "The central role of the propensity score in observational studies for causal effects," Biometrika, vol. 70, no. 1, pp. 41-55, 1983.

[29] P. R. Rosenbaum, Design of Observational Studies, Springer, New York, NY, USA, 2010.

[30] A. Aakvik, "Bounding a matching estimator: the case of a Norwegian training program," Oxford Bulletin of Economics and Statistics, vol. 63, no. 1, pp. 115-143, 2001.

[31] L. E. Pezzin and B. S. Schone, "Intergenerational household formation, female labor supply and informal caregiving: a bargaining approach," The Journal of Human Resources, vol. 34, no. 3, pp. 475-503, 1999.

[32] H. Li, T. Zhou, and C. Jia, "The influence of the universal twochild policy on China's future population and ageing," Journal of Population Research, vol. 36, no. 3, pp. 183-203, 2019.

[33] Q. Wang and M. Lin, "Work-family policy and female entrepreneurship: evidence from China's subsidized child care program," China Economic Review, vol. 54, pp. 256-270, 2019.

[34] H. Xu, "Physical and mental health of Chinese grandparents caring for grandchildren and great-grandparents," Social Science \& Medicine, vol. 229, pp. 106-116, 2019. 